\title{
Apps and Mobile Support Services in Canadian Academic Medical Libraries ${ }^{1}$
}

\author{
Tess Grynoch, BSc, MLIS ${ }^{2}$
}

\begin{abstract}
Objective: To examine how Canadian academic medical libraries are supporting mobile apps, what apps are currently being provided by these libraries, and what types of promotion are being used. Methods: A survey of the library websites for the 17 medical schools in Canada was completed. For each library website surveyed, the medical apps listed on the website, any services mentioned through this medium, and any type of app promotion events were noted. When Facebook and Twitter accounts were evident, the tweets were searched and Facebook posts were scanned for mention of medical apps or mobile services/events within the past two years. Results: All 17 academic medical libraries had lists of mobile medical apps with a large range in the number of medical relevant apps (average $=31$, median $=23$ ). A total of 275 different apps were noted and the apps covered a wide range of subjects. Five of the 14 Facebook accounts scanned had posts about medical apps in the past two years, whereas 11 of the 15 Twitter accounts had tweets about medical apps. Social media was only one of the many promotional methods noted. Outside of the app lists and mobile resources guides, Canadian academic medical libraries are providing workshops, presentations, and drop-in sessions for mobile medical apps. Conclusion: While librarians cannot simply compare mobile services and resources between academic medical libraries without factoring in a number of other circumstances, librarians can learn from mobile resources strategies employed at other libraries, such as using research guides to increase medical app literacy.
\end{abstract}

\section{Introduction}

The world is becoming increasingly mobile, with $68 \%$ of Canadians and Americans reportedly owning smart phones in 2015 [1, 2]. This mobile-rich environment has provided grounds for many innovations within the field of medicine including telemedicine, medical software for smartphones and other mobile devices, and remote patient monitoring capabilities [3]. Academic medical libraries have been quick to respond to this trend from the inception of personal digital assistants (PDAs) by providing services and access to mobile resources [4].

Previous surveys of Canadian health science students and faculty have noted a number of barriers to mobile app use including spotty wireless internet connections, a lack of understanding of how to use the resources, and the negative perceptions of professionalism while referring to mobile devices in a clinical setting [5, 6]. Many respondents have also been unaware of library-provided mobile resources. In their recent survey of pharmacy students and faculty, Duncan et al. [5] found only $51 \%$ of respondents knew of library-supplied mobile resources. Similarly, only $43 \%$ of medical students and faculty surveyed by Boruff and Storie [6] in 2012 were aware of library mobile resources, and of those only $67.5 \%$ of those students reported using them.
To overcome the lack of understanding of how to use mobile resources, academic medical libraries have organized presentations, workshops, and drop-in sessions for students and faculty. For example, library staff at the University of Utah's Spencer S. Eccles Health Sciences Library set up a help desk in the high traffic area between the cafeteria and the hospital where library patrons can stop by for help with mobile device questions and hold a monthly "Appy Hour" where new apps are highlighted [7]. Mobile drop-in sessions where users have the opportunity to test drive different apps not only teaches users how to use apps but allows users to find the app that best suits them before downloading [8]. The success of such initiatives has been short term in some cases, with attendance at mobile drop in sessions at George Washington library declining after the first year of implementation [9]. Providing training for library staff is another important component of library services for mobile apps, ensuring patrons have a consistent experience when they request help [4, 9].

For users to take advantage of these wonderful services, they first have to know they are available. Therefore, promotion is essential. Some of the promotion for mobile apps is built into the various forms of library instruction from reference interactions to class visits, but electronic and other marketing methods are needed to reach users outside of this realm. This paper addresses the questions of

Tess Grynoch. School of Management, Dalhousie University, Halifax, Nova Scotia, Canada

${ }^{1}$ This article was the recipient of the 2016 JCHLA / JABSC Student Paper Prize. This article has been peer reviewed.

${ }^{2}$ Corresponding author (email: tess.grynoch@dal.ca). ORCID: 0000-0003-0550-3961 
how Canadian academic medical libraries are supporting mobile apps, what apps are currently being provided by these libraries, and what types of promotion are being used.

\section{Methods}

In March 2016, the library websites for the 17 medical schools in Canada were reviewed (Dalhousie University, McGill University, McMaster University, Memorial University of Newfoundland, Northern Ontario School of Medicine, Queen's University, Université de Montréal, Université de Sherbrooke, Université de Laval, University of Alberta, University of British Columbia, University of Calgary, University of Manitoba, University of Ottawa, University of Saskatchewan, University of Toronto, and Western University). A search was conducted using the website or research guide's search bars for keywords such as apps, applications, mobile, medical, medicine, applis, médicales, and médecine. The medical apps listed on each website were noted along with any app-related services and events promoted through this medium. The focus was on apps supporting current/future physicians - apps targeting nurses or other health professionals were not noted unless they were integrated into a single medical apps page. For the purposes of this study, productivity tools such as citation managers, cloud storage, and flashcard apps were excluded, but any journal readers such as EBSCOhost were included. When library-sponsored Facebook and Twitter accounts were evident, tweets from the past two years were searched using Twitter's search bar, and Facebook posts were scanned from 2014 onwards for mention of medical apps or mobile services/events. If the health science library had a separate account from the main library, only the health science library social media account(s) were searched. Once the data were collected, the liaison librarian responsible for the medical app list at the institution was emailed to confirm the accuracy and completeness of the information gathered in March-April 2016. If the contact information for a medical librarian was not available, the contact information for the health science library was used. If there was no response to the email after two weeks, the medical library was contacted by phone to confirm that the email was directed appropriately. An example of the email sent to the medical librarian is provided in Supplementary Appendix A.

\section{Results}

All 17 academic medical libraries had mobile medical app information on their websites, and librarians from 15 out of 17 libraries responded to the email or follow-up phone call and corrected or verified the information found. Where no response was received, the data presented are limited to the information found on the institutions' websites, and therefore may be incomplete or inaccurate.

Canadian academic medical libraries support mobile medical apps through a number of services. All 17 libraries had a list of mobile medical apps that generally took the form of a research guide (Supplementary Appendix B). The number of apps promoted by each library ranged widely from 128 apps at the Université de Montréal to 4 apps at Western University (Figure 1). The average number of apps listed per university library is 31 , while the median number of apps is 23 . A total of 272 different apps were noted during the course of this survey, covering a wide range of subjects from general medicine and pharmacy to medical specialties such as ophthalmology. Some mobile medical app lists also included the university's app as well as those aimed at patients. The top 11 most noted apps were, in order: Dynamed, Medscape Mobile, EBSCOhost Mobile, Micomedex, Epocrates Rx, AccessMedicine, Calculate by QxMD, Diagnosaurus, UpToDate, Lexi-Comp, and PubMed.

The research guide often included other relevant information such as tip sheets on how to download apps,

Fig. 1. Number of apps highlighted on academic medical library websites at the 17 Canadian medical universities.

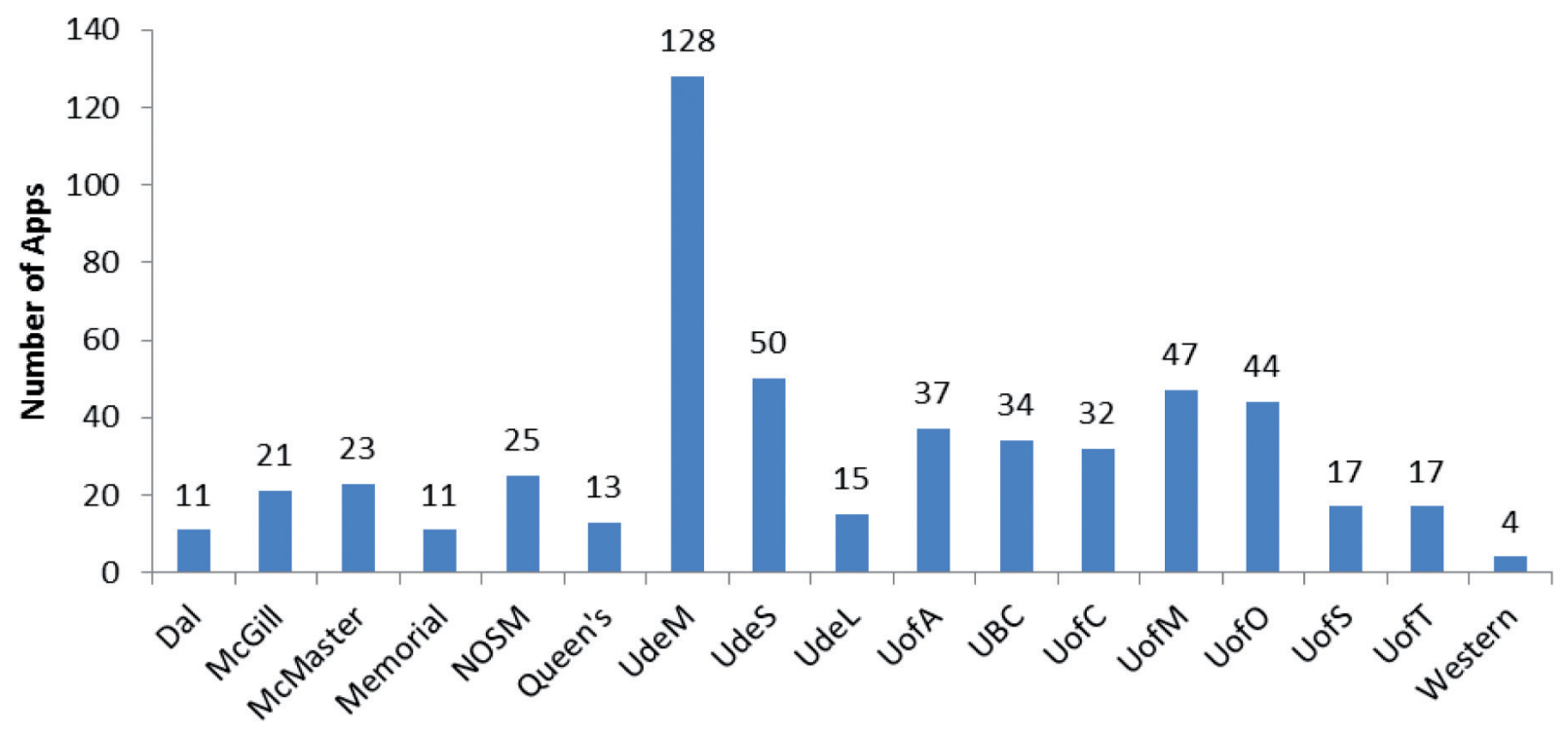


configure mobile devices with the university proxy, and how to use a particular resource. The guides would often provide links to app review resources, the most popular of which was www.iMedicalApps.com with mhq.dmdpost. com as a frequent site for French app reviews. Contact information for help was also a common feature on mobile medical app research guides whether the contact information was for an individual librarian, the health sciences library, or the information technology department. One of the guides even had an embedded chat function. A unique feature on the Université de Montréal and the Université de Sherbrooke's guides were sections on security and privacy considerations when using apps in a clinical setting. These two guides also provided tips on how to evaluate apps for clinical use.

Outside of the app lists and mobile resources guides, Canadian academic medical libraries are providing workshops and presentations on mobile medical apps. Some appear to be one-time events while others, such as the library instruction provided at Memorial University of Newfoundland, are embedded into the medical curricula. Some of the libraries have put together engaging mobile app drop-in sessions such as the App Petting Zoo at the University of Toronto where users where encouraged to try out some of the library's apps on an iPad stationed outside of the library and Download Day at Queen's University where users were encouraged to drop by the library for help downloading apps.

Promotion of apps through social media varied between institutions. Fourteen of the 17 libraries scanned had active Facebook accounts, whereas 15 had active Twitter accounts (Table 1). Five of the Facebook accounts had posts about medical apps in the past 2 years, whereas 11 Twitter accounts had tweeted about medical apps (Figure 2). Other noted promotion methods include the use of other social

Table 1. Canadian academic medical libraries with Facebook and (or) Twitter accounts.

\begin{tabular}{lcc}
\hline University & $\begin{array}{c}\text { Facebook } \\
\text { account }\end{array}$ & $\begin{array}{c}\text { Twitter } \\
\text { account }\end{array}$ \\
\hline Dalhousie University & Yes & Yes \\
McGill University & Yes & Yes \\
McMaster University & Yes & Yes \\
Memorial University of & Yes & Yes \\
$\quad$ Newfoundland & & \\
Northern Ontario School of & Yes & Yes \\
$\quad$ Medicine & & \\
Queen's University & Yes & Yes \\
Université de Montréal & Yes & Yes \\
Université de Sherbrooke & Yes & No \\
Université de Laval & Yes & Yes \\
University of Alberta & Yes & Yes \\
University of British Columbia & Yes & Yes \\
University of Calgary & Yes & Yes \\
University of Manitoba & Yes & Yes \\
University of Ottawa & No & Yes \\
University of Saskatchewan & No & No \\
University of Toronto & No & Yes \\
Western University & Yes & Yes \\
\hline
\end{tabular}

media platforms such as Tumblr, digital displays, bulletin boards, blogs and library news outlets, banner advertisements on the library's home page, or posting on departmental Facebook accounts. In their responses to the follow-up email, many librarians stated that mobile resources were also promoted through library workshops and orientation sessions. The Université de Montréal also promotes their expertise in mobile apps through publishing in local professional journals for clinicians and in interviews with local newspapers and radio.

\section{Discussion}

Certain factors prevent a fair comparison of apps at different academic medical libraries. Such factors include the language(s) used to teach courses at the university, as French apps were only listed for libraries that supported Francophone universities. Some medical departments have a mandatory device, which limits the number of mobile apps to the applicable operating systems, or they host their own list of mobile resources. The responsibility of some academic medical libraries to support surrounding medical institutions may have also led to a higher number of patient-targeted resources promoted. If all medical apps currently available were placed on a research guide, users would not only be overwhelmed, but the guide would also need to be updated every week. The optimal number of apps would depend on the local context of the library.

Although there was a large variation in the number and types apps provided at Canadian academic medical libraries, the most popular apps listed on library websites aligned closely with the most popular resources identified in Boruff and Storie's survey [5]. Eight of the top 10 favorite resources from Boruff and Storie's survey [5] also appeared as the top most frequently listed apps on the library websites studied including UpToDate, Epocrates, Medscape/eMedicine, LexiComp, PubMed, DynaMed, a medical calculator, and Micromedex (Table 2). The only app from the top 10 in Boruff and Storie's survey [5] to not make the top 11 in this study (besides the web browser) was PEPID, which was 15th. Not all of the apps listed on the library websites needed library subscriptions. A recent survey of medical

Fig. 2. Number of academic medical libraries that support medical programs with Twitter and Facebook accounts and how many libraries used the respective accounts to promote mobile apps.

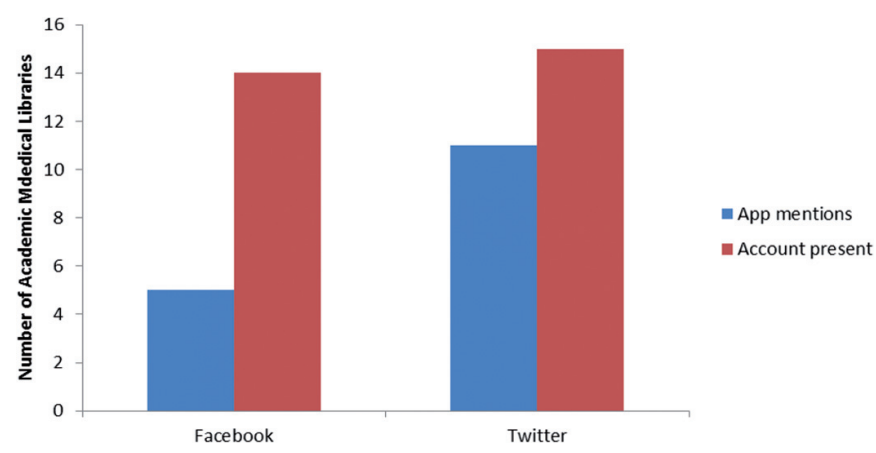


Table 2. Top 11 most frequently listed medical apps on library websites surveyed compared with how frequently apps were mentioned by participants in Boruff and Storie's survey [5].

\begin{tabular}{|c|c|c|c|}
\hline App & $\begin{array}{l}\text { Number of } \\
\text { libraries that } \\
\text { listed app } \\
\text { (out of 17) }\end{array}$ & $\begin{array}{l}\text { Percentage of participants that listed } \\
\text { app as a favorite in Boruff and } \\
\text { Storie's survey [5]* }\end{array}$ & $\begin{array}{c}\text { Percentage of participants that mentioned app when } \\
\text { asked about the last time they used mobile device to } \\
\text { lookup medical information in Boruff and Storie's } \\
\text { survey [5] }\end{array}$ \\
\hline DynaMed & 15 & 5.6 & 5.8 \\
\hline Medscape Mobile & 14 & 11.4 & 12.8 \\
\hline EBSCOhost Mobile & 13 & NA & NA \\
\hline Epocrates Rx & 11 & 11.4 & 8.7 \\
\hline $\begin{array}{l}\text { Calculate by QxMD } \\
\text { (medical calculator) }\end{array}$ & 10 & $5.0 \%$ & $7.7 \%$ \\
\hline Diagnosaurus & 8 & NA & NA \\
\hline Lexi-Comp & 8 & 10.2 & 9.8 \\
\hline PubMed & 8 & 6.8 & 9.9 \\
\hline
\end{tabular}

*In Boruff and Storie's survey, participants were allowed to choose more than one app.

Note: NA, not available.

students in 2014 revealed that two of the most used apps, ePocrates and Medscape, were free apps [10].

Canadian medical libraries have addressed app promotion in numerous ways. Many of the promotional tools employed were similar to those cited in the literature such as social media, public display screens, websites, printed material, outreach, and training [7, 11, 12]. One promotional strategy noted in the literature that was not mentioned by respondents in this study was the use of email [11]; although, one librarian did note that they chose not to use email for promotion due to users complaining of email fatigue. Social media, while an easy method to promote services and resources to a large audience, is problematic in terms of reaching an academic medical library's target audience. Not only does hospital IT frequently block access to social media sites for privacy and security reasons [11], students and staff are viewed as unlikely to follow the library on social media [13]. One respondent indicated that they felt resources were best reallocated elsewhere. Other potential methods suggested through the literature include using campus- or organization-wide events as potential platforms for promoting mobile resources [12] and reaching out and developing connections with internal resources such as IT departments and education departments [11]. Université de Montréal did this by using the medical department's Facebook page to post information. If students do not follow the library, they may be more likely to follow their student group or department. Université de Montréal also expanded their promotion beyond the university through use of public mass media such as radio and newspapers and professional newsletters.

The survey revealed some variations on app support services that were not highlighted in the literature such as the addition of tip sheets, links to mobile app review resources, contact information for help, and app literacy information on the same mobile guide. The presence of sections on security and privacy on the Université de Montréal and the Université de Sherbrooke's guides along with tips on how evaluate apps for clinical use appear to address the concerns of professionalism $[6,10]$. The area of app literacy has already produced a set of app evaluation criteria created by DeRosa and Jewell [12] that includes: subject relevance, quality of content (quality in content, format, and merit), reputation of producer/publisher, cost, access (functionality and usability), legal issues (access to terms of service should be quick and easy), copyright, and fair use issues. These evaluation criteria could be used to provide further mobile app support as tips during a mobile app literacy session or guide for health professionals and patients [12]. A similar app literacy course was taught at the Preston Medical Library at the University of Tennessee [14].

\section{Conclusions and further research}

Future research on mobile app support could include schools that support other professional health education streams such as nursing, physiotherapy, and natural medicine. The survey could also be expanded geographically to locations beyond Canada such as the United States. In the benchmarking survey for mobile app services performed by the New York University Health Sciences Libraries in 2010, they also looked at where users were directed to help [15]. A similar question could be added to the website scan, noting if a specific contact person or a generic university email is provided. The data collected through this survey could also be combined with mobile app usage statistics at different libraries to compare the effectiveness of different mobile app services and promotion strategies, although these data would need to be considered in light of the differences in populations served by the various libraries.

Further usability testing could also be performed to discover which method of mobile app guide organization is most conducive to users finding the app they want and determine how symbols and icons used in the guides could be used to their best advantage. The same testing could determine how to indicate apps that require an internet 
connection, which was one of the barriers noted in previous research [5].

While librarians cannot simply compare mobile services and resources between academic medical libraries without considering the local context, librarians can learn from the promotional strategies employed at other libraries. For example, the survey revealed how commonly used tools such as the research guide can be employed to increase medical app literacy and raise awareness of security and privacy concerns associated with their use. In the wider field of academic librarianship, other subject-specific libraries can learn from the successful services and promotional strategies used by these early mobile app adopters.

\section{References}

1. Catalyst. The Canadian mobile market in 2015 [Internet]. Toronto: Catalyst Canada; c2015-2016 [cited 29 Mar 2016]. Available from: http://catalyst.ca/2015-canadian-smartphonemarket/

2. Pew Research Center. The demographics of device ownership [Internet]. Washington, DC: Pew Research Center; c2015 [cited 6 Jul 2016]. Available from: http://www.pewinternet. org/2015/10/29/the-demographics-of-device-ownership/

3. Atienza AA, Patrick K. Mobile health: the killer app for cyberinfrastructure and consumer health. Am J Prev Med. 2011;40(5 Supp12):S151-S153. doi: 10.1016/j.amepre.2011. 01.008 .

4. Crowell K, Shaw-Kokot J. Extending the hand of knowledge: promoting mobile technologies. Med Ref Serv Q. 2003; Spring;22(1):1-9. doi:10.1300/J115v22n01_01.

5. Boruff JT, Storie D. Mobile devices in medicine: a survey of how medical students, residents, and faculty use smartphones and other mobile devices to find information. J Med Libr Assoc. 2014;102(1):22-30. doi:10.3163/1536-5050.102.1.006.

6. Duncan V, Vokey S, Gordon S, Helwig M, Chatterley T. Mobile device use in pharmacy: a multi-institutional study.
$J$ Can Health Libr Assoc/J de l'Assoc des biblio de la santé du Can. 2015;36(3):106-113. doi:10.5596/c15-021.

7. Casucci T. Driving innovation in mobile learning and libraries. Paper presented at: SLA 2015. Proceedings of the Special Libraries Association Conference 2015; 2015 Jun 14-16; Boston, MA.

8. Capdarest-Arest N, Glassman NR. Keeping up to date: apps to stay on top of the medical literature. J Electron Resour Med Libr. 2015;12(3):171-181. doi:10.1080/15424065.2015. 1065660

9. Gomes A, Abate L. Rethinking our mobility: supporting our patrons where they live. Med Ref Serv Q. 2012;31(2): 140-149. doi:10.1080/02763869.2012.670574.

10. Stokes A, Light J, Haines LL. Library support of mobile resources during clinical clerkships. Med Ref Serv Q. 2014; 33(2):179-194. doi:10.1080/02763869.2014.897519.

11. Chamberlain D, Elcock M, Puligari P. The use of mobile technology in health libraries: a summary of a UK-based survey. Health Info Libr J. 2015;32(4):265-275. doi:10.1111/ hir. 12116.

12. DeRosa AP, Jewell ST. Establishing a mobile resources collection development policy. J Electron Resour Med Libr. 2014;11(3):144-154. doi:10.1080/15424065.2014.939000.

13. Wu J, Chatfield AJ, Hughes AM, Kysh L, Rosenbloom MC. Measuring patrons' technology habits: an evidence-based approach to tailoring library services. $\mathrm{J}$ Med Libr Assoc. 2014;102(2):125-129. doi:10.3163/1536-5050.102.2.014.

14. Lindsay JM, Earl MF. Investigating mobile device use by medical residents, nurses, and consumers. J Consum Health Internet. 2014;18(1):1-14. doi:10.1080/15398285.2014.869164.

15. Graham J, Maher S, Moore D, Morton-Owens E. Taking the library to the clinic: building mobile services for a medical library. Ref Lib. 2012;53(3):326-345. doi:10.1080/02763877. 2012.679856. 